\title{
Avian malaria prevalence and mosquito abundance in the Western Cape, South Africa
}

\author{
Sharon Okanga*, Graeme S Cumming and Phillip AR Hockey
}

\begin{abstract}
Background: The close relationship between vector-borne diseases and their environment is well documented, especially for diseases with water-dependent vectors such as avian malaria. Mosquitoes are the primary vectors of avian malaria and also the definitive hosts in the disease life cycle. Factors pertinent to mosquito ecology are likely to be influential to observed infection patterns; such factors include rainfall, season, temperature, and water quality.

Methods: The influence of mosquito abundance and occurrence on the prevalence of Plasmodium spp. in the Ploceidae family (weavers) was examined, taking into account factors with an indirect influence upon mosquito ecology. Mosquitoes and weaver blood samples were simultaneously collected in the Western Cape, South Africa over a two-year period, and patterns of vector abundance and infection prevalence were compared. Dissolved oxygen, $\mathrm{pH}$, temperature and salinity measurements were taken at 20 permanent waterbodies. Rainfall during this period was also quantified using remotely sensed data from up to 6 months prior to sampling months.
\end{abstract}

Results: Sixteen wetlands had weavers infected with avian malaria. More than half of the mosquitoes caught were trapped at one site; when this site was excluded, the number of mosquitoes trapped did not vary significantly between sites. The majority of mosquitoes collected belonged to the predominant vector species group for avian malaria (Culex culex species complex). Seasonal variation occurred in infection and mosquito prevalence, water $\mathrm{pH}$ and water temperature, with greater variability observed in summer than in winter. There was a significant correlation of infection prevalence with rainfall two months prior to sampling months. Mosquito prevalence patterns across the landscape also showed a close relationship to patterns of rainfall. Contrary to predictions, a pattern of asynchronous co-variation occurred between mosquito prevalence and infection prevalence.

Conclusion: Overall, salinity, rainfall, and mosquito prevalence and season were the most influential vector-related factors on infection prevalence. After comparison with related studies, the tentative conclusion drawn was that patterns of asynchronous variation between malaria prevalence and mosquito abundance were concurrent with those reported in lag response patterns.

Keywords: Avian malaria, Mosquito, Western Cape, South Africa

\section{Background}

Outbreaks of vector-borne diseases have increasingly been linked to human activities. As people alter landscapes through such activities as forestry, ranching, and agriculture, they may influence disease epidemiology in a variety of ways [1]. In addition to its direct effects on interactions between pathogens and their vectors and hosts, landscape change can alter disease dynamics indirectly via changes in vector ecology. In the case of avian malaria, for example,

\footnotetext{
* Correspondence: sokanga@gmail.com

Deceased

Percy FitzPatrick Institute, DST/NRF Centre of Excellence, University of Cape Town, Rondebosch, Cape Town 7701, South Africa
}

the influence of host-pathogen relationships on malaria prevalence is fairly well documented [2-4]. However, the impacts of vector ecology and environmental changes on vector ecology are poorly understood. This uncertainty adds a measure of complexity to the prediction of malaria transmission rates.

Mosquitoes are the main vector group for avian malaria [5]. Mosquito abundance is often influenced by environmental factors such as temperature, rainfall, water quality, and habitat [6]. Vector groups for both human malaria (Anopheles mosquitoes) and avian malaria (Culex mosquitoes, Culex quinquefasciatus and C. univitattus)

\section{Biomed Central}


demonstrate sensitivity to temperature changes [7]. Further complexity in the epidemiology of avian malaria is introduced by other unknowns, such as the blood meal frequency of infected mosquitoes, transmission rates, and the ratio of vectors to birds in a given habitat [8-10]. Research indicates that anthropogenic activities often alter water quality and availability, and may influence the amount of rainfall that a locality or region receives $[11,12]$. Such trends will alter the infection patterns of water-borne pathogens and those with water-dependent vectors. The impacts of environmental change on vector-borne diseases may be further enhanced if the vector plays an amplifying role in the pathogen's life history, as in the case of avian malaria lifecycle, in which sexual reproduction of haemosporidia occurs in the mosquito [5].

Environmental influences on pathogen success have been observed in other host-pathogen systems. For example, the role of water quality is evident in the case of avian influenza prevalence in waterfowl, which co-varies with water salinity [13]. In the lifecycle of Schistosoma, snail vectors show faster growth rates when food availability (plant production) is increased in nutrientenriched waters [14]. Human malaria prevalence is also influenced by water quality, which affects the breeding success of mosquito vectors. Kengluecha et al. [15] found that Anopheles species abundance fluctuated in accordance with changes in water temperature, $\mathrm{pH}$ and dissolved oxygen. The dependence of the mosquito lifecycle on water is strong enough that it can influence patterns of infection at regional extents. For instance, Wood et al. [16] showed an apparent pattern of higher infection prevalence in nesting sites of blue tits, Parus caeruleus, closer to the River Thames, as a result of increased vector abundance near the water.

The generality of many of these results is unclear. As a test of our emerging understanding of avian malaria ecology, we used a case study in the Western Cape of South Africa to test the following predictions: (1) the infection prevalence of avian malaria would vary with vector abundance; (2) vector abundance and infection prevalence would vary with season and rainfall (with more rainfall encouraging higher prevalence of vectors and avian malaria); and (3) vector type and species would vary with water quality, which would reflect in prevalence patterns.

\section{Methods}

\section{Sampling sites}

Research was conducted after approval from the Science Faculty Animal Ethics Committee, University of Cape Town and carried out in strict accordance with the recommendations given by the committee. Research did not involve the sampling of endangered or protected species. Access to field sites was granted by private landowners in the Western Cape and the City of Cape Town. Research permits granting access to protected areas were issued by SANParks (South African National Parks Board) and by Cape Nature (the Western Cape Nature Conservation Board).

Sampling was conducted at 20 perennial wetlands of $1-10$ hectares in size, in the Western Cape Province of South Africa [17]. Wetlands were chosen as study sites, as they are resource-rich and act as key habitats for a large variety of birds [18]. All sites were located between altitudes of $0-300 \mathrm{~m}$ above sea level. In the Western Cape, summer occurs in the months of January to March, and winter in the months of July to September. Unlike other parts of South Africa, the Cape region experiences winter rainfall. The Cape is currently devoid of human malaria, but has a history of avian malaria infection [19-21]. Sites were visited once per year for two years (between 2010 and 2011). Samples were collected during each visit; visits were timed to ensure that each site was visited once during summer and once during winter, with samples collected during each visit.

\section{Sampling of birds}

Birds from the Ploceidae family (bishops, weaver birds, and allies - hereafter referred to as 'weavers') were the target group and were trapped using mist nets. Although weavers can be highly mobile, the species trapped were mostly residential [22]. In keeping with their social nature, weavers tend to move en masse and live in nests built close together, and situated over water surfaces [22]. It is, therefore, quite likely that infected birds caught at a particular site were infected at the same sampling site.

Birds were sampled by pricking the brachial vein and collecting blood into a capillary tube [23], which was then preserved in vials containing lysis buffer. The vial was sealed and the sample sent for molecular processing. All birds were ringed (to identify potential recaptures) and released after sampling.

\section{Molecular analysis}

Blood samples were analysed using PCR, as detailed by Cumming et al. [24]. MEGA 5.0 (Molecular Evolutionary Genetics Analysis [25]) was used to conduct genetic analyses, to choose the most appropriate model of evolution, and to construct maximum likelihood (ML) phylogenetic trees. In addition, a Bayesian analysis was run in MR Bayes for 1 million generations with a burnin of 250000 generations, sampling one in every 100 trees [26,27]. The general time reversible model with a discrete gamma distribution $(\mathrm{GTR}+\mathrm{G} ; \mathrm{G}=0.20)$ received the best Bayesian Information Criterion score and 
was applied to the ML Bayesian phylogenetic analysis. Node support was evaluated using 1,000 bootstrap replicates, with bootstrap values greater than $50 \%$ used for the final tree [28]. Sample sequences emerging in the same branches as GenBank sequences were assumed to be the same species and in this study are collectively referred to as a 'clade'. Seven individual Plasmodium spp. lineages were isolated altogether, with clades numbered from I-VII. Two dual infection types were also isolated and were represented with the numbers of each clade causing infection.

\section{Mosquito sampling}

Mosquitoes were trapped using two CDC miniature light traps (model 512, John W. Hock company). The traps were placed at opposite ends of the wetland, or at least $200 \mathrm{~m}$ from each other, to avoid overlap in the areas being sampled. Traps were suspended approximately 1.5 metres above ground, from a tree or bush and placed at a distance not exceeding $20 \mathrm{~m}$ from the water's edge. Traps were operated using a 6 volt lead-acid motor cycle battery, which would run a trap for two nights when fully charged. Traps were placed out from dusk until dawn in 12 hour trapping cycles, after which they were retrieved. Trapping sessions consisted of one to two nights per site, depending on the numbers of mosquitoes trapped and the success of the trap location. Mosquitoes in the trap were individually removed and placed into a $10 \mathrm{ml}$ vial containing absolute ethanol.

In the laboratory, vials were decanted into a petri dish with filter paper. Mosquitoes were separated from the other insects caught in the trap, and left to dry on a separate piece of dry filter paper. Dried mosquito specimens were individually examined and identified using a Nikon SMZ-10 stereomicroscope. Identification of mosquito specimens was facilitated by the use of a handbook detailing local South African species and their distributions [29]. This handbook is specific only to the identification of female mosquitoes in the Culicinae and Toxorhynchitinae families. Anopheles mosquitoes and male culicine specimens were sent for identification to the VCRU (Vector Control Reference Unit) at the NCID (National Institute for Communicable Diseases, Johannesburg, South Africa), together with specimens that could not be identified using the handbook. Mosquito species were noted as potential vectors in accordance with Russell and Mohan [30], Njabo et al. [31] and Ventim et al. [32].

\section{Water quality}

Water quality was measured at each wetland site using an HI 9828 Hanna handheld water meter (HANNA instruments). Water samples were taken from three stations situated at opposing points around the wetland and sampled consistently at the same points during all sessions. Measurements recorded were dissolved oxygen, temperature, $\mathrm{pH}$ and salinity. Measurements were made every two metres into the water body, starting at $1 \mathrm{~m}$ from the shoreline up to a distance of $20 \mathrm{~m}$, or as far into the waterbody as depth would allow. Sampling was conducted once during summer and once during winter for each site.

\section{Rainfall}

Rainfall data were obtained from the FEWS (Famine Early Warning Systems) net portal [33]. The site provides remote spatial data for various regions worldwide, including estimates of daily rainfall (RFE). RFE is calculated using a rainfall estimation algorithm that incorporates cloud top temperature and rainfall data from various stations acquired at six-hour intervals at a resolution of 0.25 degrees [34]. RFE data were downloaded from the southern Africa region files available on the site.

The daily rainfall data were summed to give a monthly rainfall estimate (MRFE), as well as seasonal and annual rainfall estimates for each site. MRFEs, together with the number of days of rainfall per month, were calculated for up to six months prior to the sampling month (i.e. over the period of July 2009 to September 2011). This was done in accordance with the results of Mbogo et al. [35], who showed that vegetation, mosquito abundance and infection prevalence display a lag response to rainfall patterns, and that rainfall (and days of rainfall) from preceding months can potentially influence disease infection prevalence.

\section{Statistical analysis}

All statistical analysis was conducted in R (2011_12_22) [36]. Samples were ordered by season collected (winter or summer). Readings from all sampling stations were collated to generate a mean value for each parameter measured per site for each season, and all parameters were used in analysis.

All variables were tested for normality using the Shapiro-Wilkes test. Only salinity was non-normal. To reduce heteroscedasticity in models [37], salinity data were log-transformed using a Box-Cox transformation [38], dividing by the mean and adding a constant as per the following equation:

$$
\text { salinity }^{\prime}=\log (\text { salinity } / \text { mean }(\text { salinity })+k)
$$

where $\mathrm{k}$ is a constant $>0$.

Because water quality tends to display spatial heterogeneity in accordance with varying altitude and geology in a landscape [39], the longitudinal and latitudinal 


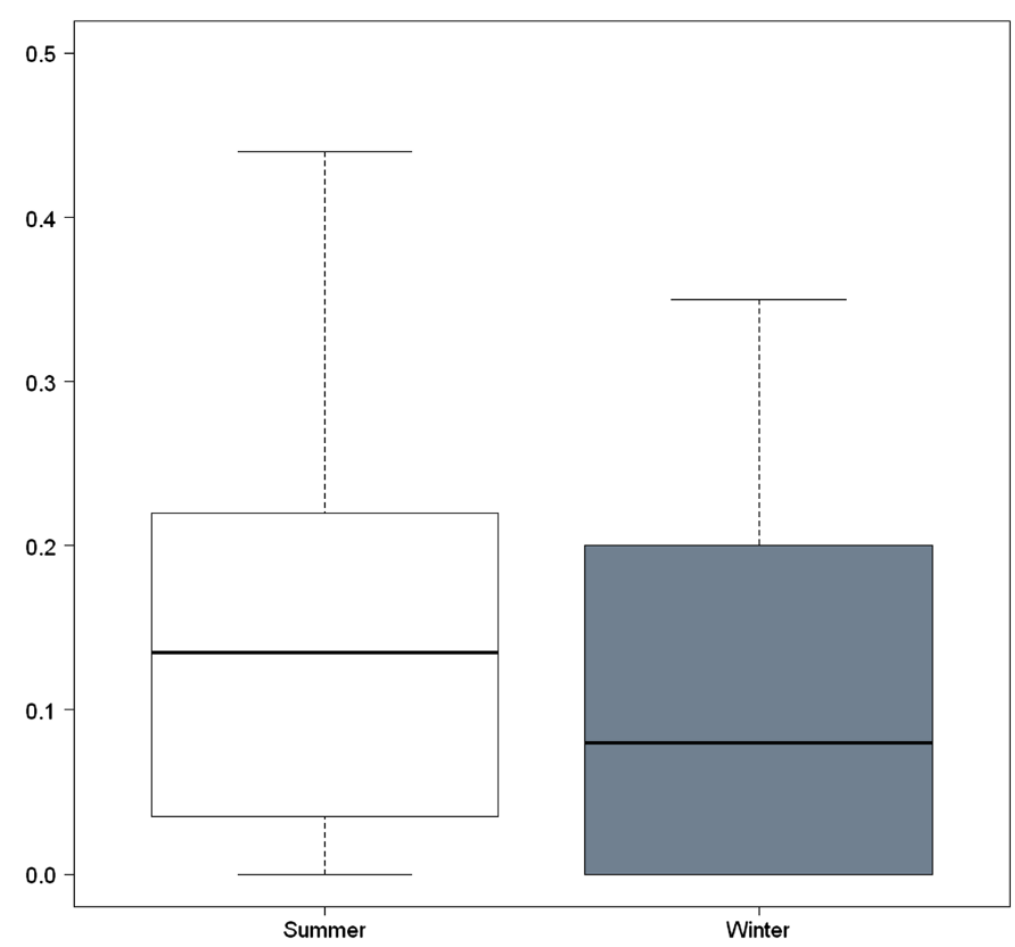

Figure 1 Seasonal prevalence of Plasmodium infections amongst weaver birds.

values of each wetland site were also included as explanatory parameters in multiple regression analysis.

Some mosquito specimens were unidentifiable due to immaturity and key body parts missing, and were not included in analysis. Mosquito data were quantified in two ways: mosquito prevalence and vector abundance. Mosquito prevalence was calculated as the sum of mosquitoes caught per site divided by total number of mosquitoes caught overall. For sites where trapping was conducted over two nights, the mean number of mosquitoes caught was calculated to provide comparability with sites where mosquitoes were trapped over one night.

As data for vector species for avian malaria are still quite sparse for the Western Cape region, there remains the possibility that additional undocumented species act as vectors. We simply used the abundance of known

Infected

口Caught

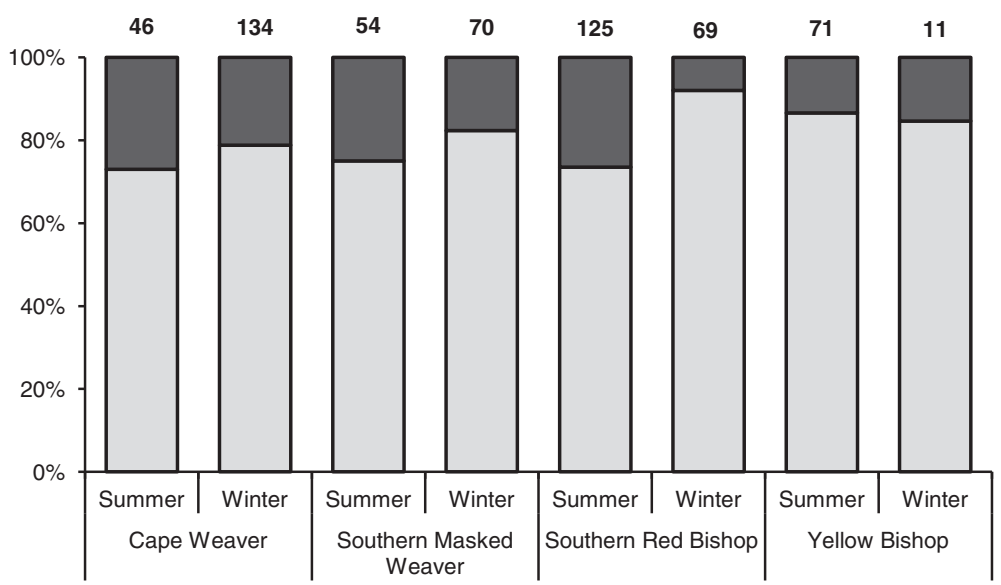

Figure 2 Seasonal infection prevalence of infected weavers. The number of birds caught per species is indicated above each column $(n=580)$. 
vectors to gauge vector presence. Vector abundance was thus the number of known vectors caught per site.

A disproportionate number of mosquitoes were caught at one wetland site. Because trapped mosquito samples displayed a non-normal distribution, the inter-quartile range of the dataset was employed as an outlier identification method applicable to non-normally distributed data [40], to identify outliers as per the following:

$$
\text { Outlier }>1.5\left(Q_{3}-Q_{1}\right)
$$

And extreme outliers as:

$$
\text { Extreme Outliers }>\left(Q_{3}-Q_{1}\right)
$$

Where $\mathrm{Q}_{1}=1^{\text {st }}$ quartile; $\mathrm{Q}_{3}=3^{\text {rd }}$ quartile.

The number of mosquitoes caught at this wetland site qualified as an extreme outlier in the dataset. Consequently, mosquito abundance data were analysed with and without the inclusion of this site in the data, to compensate for potential distortion in regression analyses.

Simple and multivariate regression was used to explore the relationships between infection prevalence and mosquito/vector prevalence, water quality and vector prevalence, and water quality and infection prevalence. Pearson's product-moment correlations $\left(r^{2}\right)$ were run between infection prevalence and water quality elements, infection prevalence and mosquito/vector abundance; and mosquito/vector abundance and water quality. Significant variation within and between water quality parameters, seasonal infection prevalence, and the number of mosquitoes caught was tested using Chi-squared test, Welch's two tailed $t$-test and ANOVA.

Multiple regression analyses were run using general linear models (GLMs) fitted with Poisson (canonical) links corresponding to the nature of the prevalence distribution.

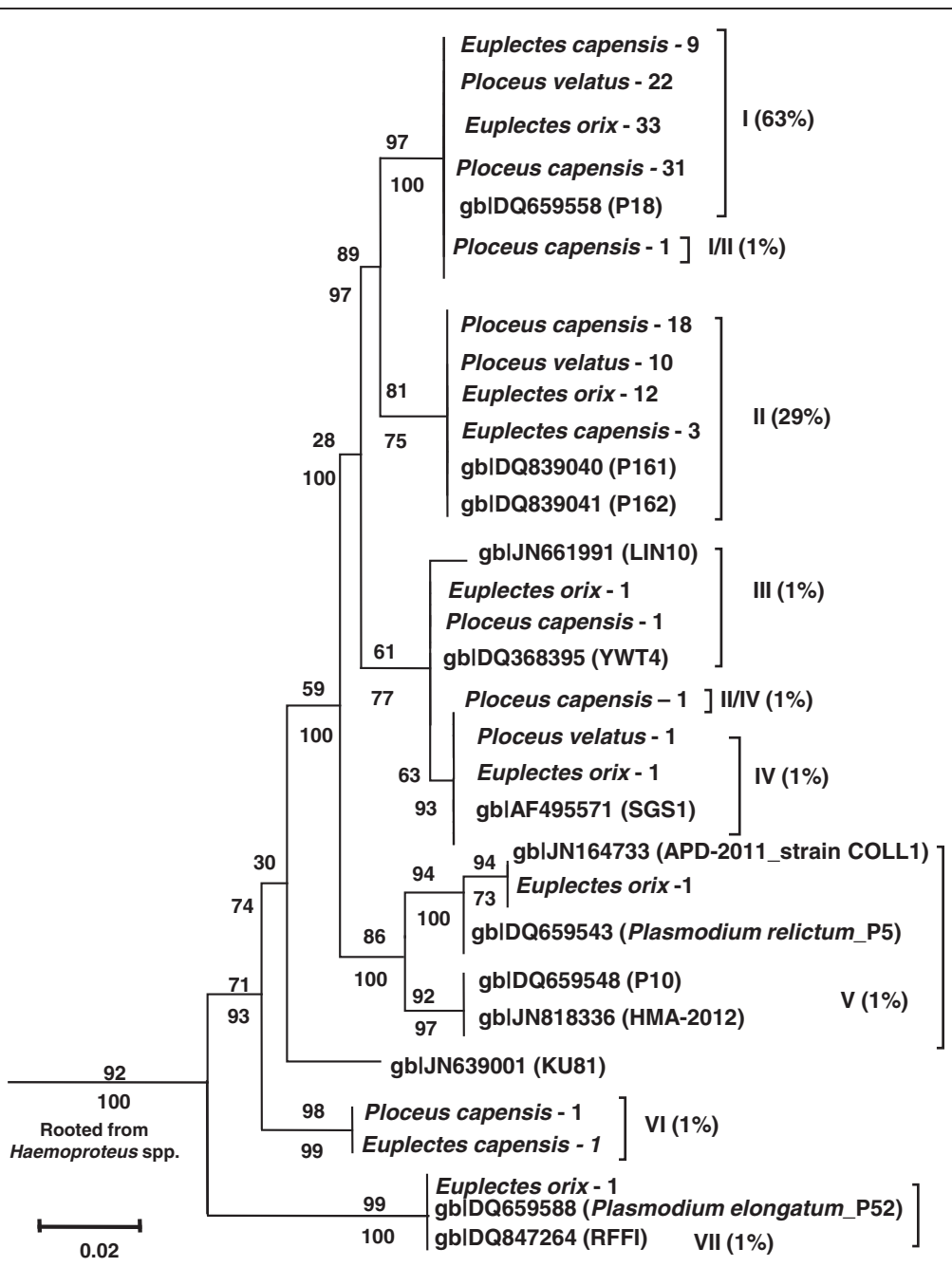

Figure 3 Plasmodium phylogenetic tree with bootstrap values ( $\mathbf{5 0} \%$ ) displayed. Nodal support values from maximum likelihood analysis are displayed above branches and those from Bayesian analysis are below. Letters identify the clade $(n=9)$ with clade infection prevalence in brackets $(n=150)$. Weaver species infected are Ploceus capensis (Cape Weaver), Ploceus velatus (Southern Masked Weaver), Euplectes orix (Southern Red Bishop) and Euplectes capensis (Yellow Bishop). Matching or closely related lineages from Genbank are also displayed in the tree. 
Model selection was conducted using Akaike's Information Criterion value (AIC) as the indicator of the best-fit model. Model selection was conducted using values from Akaike's information criterion (AIC) as an indicator of the best-fit model, with predictor variables retained or removed depending upon their effect upon model AIC value.

\section{Results}

\section{Overall results}

From 20 sites, 150 (27\%) weavers out of 580 sampled birds were infected with Plasmodium spp.; only 4 sites had no infected birds. 524 mosquitoes were caught from 16 sites, with 345 (66\%) caught at Strandfontein (STR). Mosquitoes trapped did not vary significantly between sites, after analysis including data from $\operatorname{STR}\left(F_{1,24}=0.07\right)$ and excluding $\operatorname{STR}\left(F_{1,24}=0.27\right)$.

\section{Seasonal variation in infection prevalence and lineage prevalence}

Out of the total sampled population, ninety-one weavers (16\%) were infected during summer sampling months and 59 weavers $(10 \%)$ were infected during winter sampling. Overall infection prevalence displayed significant seasonal variation (Figure $1 ; x^{2}=180$; d. f. $=81 ; p<$ 0.001). Southern Red Bishops were the most abundant weaver species caught and also were the most heavily infected weaver species, with $26 \%$ of caught birds infected (Figure 2). Southern Red Bishops were also the only species to display significant variation in infection prevalence between seasons $\left(x^{2}=21.86 ; p<0.001\right)$, with most birds infected during the summer.

\section{Variation in lineage prevalence}

Clade I was the predominant lineage occurring throughout both seasons. It infected more birds than any other lineage, and also occurred in one of two dual infections observed (Figure 3). Two birds also displayed dual infections. Plasmodium lineages mainly occurred during the summer, with only four lineages also occurring during winter (Figure 4). However, no significant difference was found in prevalence for lineages occurring both in summer and winter $(t=0.46 ;$ d. f. $=14.48 ; p=0.65)$.

\section{Variation in mosquito and vector abundance}

Fifteen species from five genera were identified from 153 specimens ( $40 \%$ of the total catch), as listed in Table 1. Five of these species, from the Culex genus and Culiseta genera, are known vectors of avian malaria.

Mosquito abundance varied significantly between seasons (Figure 5): 490 individuals (between 1-260 specimens per site) were caught in the summer from 14 sites, whereas only 34 ( $1-8$ specimens per site) were caught in winter from eight sites $\left(t=2.13_{1}, 38 ; p=0.04\right)$. Overall, Plasmodium infection per site showed little correlation with vector abundance $\left(r^{2}=-0.29 ; p=0.21\right)$. Mosquito seasonal prevalence and Plasmodium infection were not significantly correlated $\left(r^{2}=-0.28 ; p=0.08\right)$, although this association strengthened notably after the exclusion of STR mosquitoes $\left(r^{2}=-0.33 ; p=0.04\right)$.

\section{Water quality, infection and vector prevalence}

Seasonal variation also occurred in water quality elements measured (Table 2). Temperature varied clearly from summer to winter $\left(t=11.98_{1}, 33.74 ; p<0.001\right)$, with higher temperatures occurring in summer. There was significant variation in $\mathrm{pH}$ values $\left(t=2.09_{1}, 36.56 ; p=\right.$ 0.04 ), with increasing alkalinity observed during winter.

Only salinity was correlated with infection prevalence $(r=0.39$; d. f. $=38 ; p<0.03)$, with Plasmodium prevalence increasing with rising salinity values (see Table 3 ). There was also significant correlation between vector

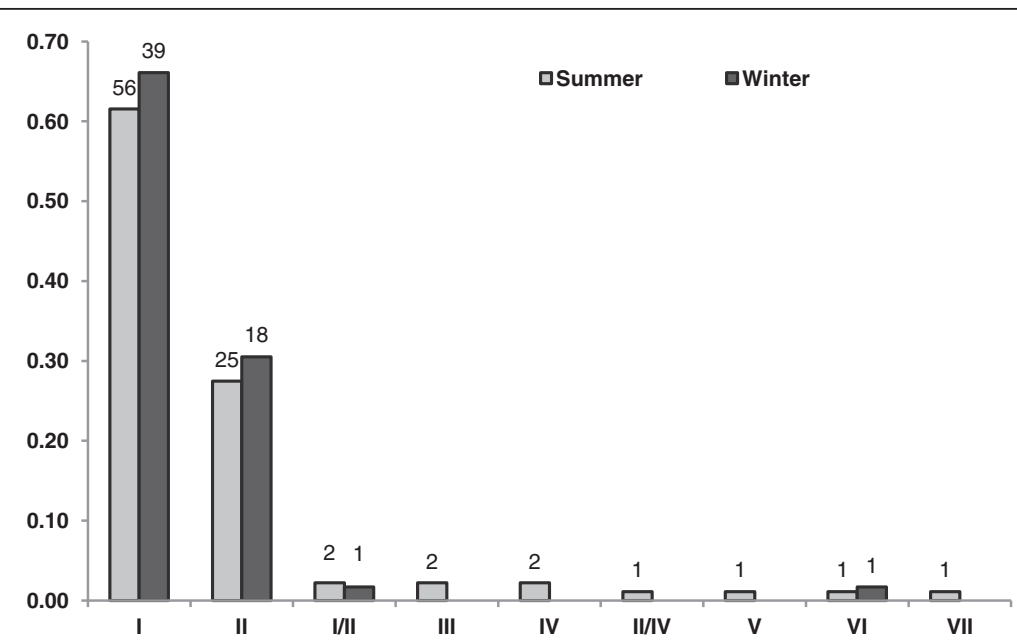

Figure 4 Seasonal infection prevalence of Plasmodium lineages. The number of birds infected per lineage is indicated above each column ( $n=150$ ). 
Table 1 Mosquito species caught across sites $(\mathbf{n}=\mathbf{5 2 4})$

\begin{tabular}{lllll}
\hline Mosquito species & $\begin{array}{l}\text { Sites } \\
\text { present }\end{array}$ & Summer & Winter & $\begin{array}{l}\text { Total } \\
\text { catch }\end{array}$ \\
\hline $\begin{array}{l}\text { Culex Culex } \\
\begin{array}{l}\text { Culex culex pipiens complex } \\
\text { (. }\end{array}\end{array}$ & 9 & 44 & 2 & 46 \\
C. c. theileri* & 9 & 20 & 5 & 25 \\
C. c. univitattus* & 6 & 14 & 6 & 20 \\
C. c. decens & 4 & 6 & 0 & 6 \\
C. c. chorleyi & 2 & 3 & 0 & 3 \\
C. c. andersoni bwana & 1 & 1 & 0 & 1 \\
C. c. simpsoni & 1 & 1 & 0 & 1 \\
Total & & $\mathbf{9 2}$ & $\mathbf{1 3}$ & $\mathbf{1 0 5}$ \\
& & & $\mathbf{6 7 \% )}$
\end{tabular}

\section{Culex culiciomyia}

\begin{tabular}{lllll} 
C. culiciomyia cinerellus & 1 & 1 & 0 & 1 \\
Total & & $\mathbf{1}$ & $\mathbf{0}$ & $\mathbf{1}(\mathbf{0 . 6 \% )}$ \\
\hline
\end{tabular}

Culex eumelanomyia

\begin{tabular}{lllll}
$\begin{array}{l}\text { C. eumelanomyia } \\
\text { inconspicuosus }\end{array}$ & 4 & 6 & 1 & 7 \\
$\begin{array}{l}\text { C. e. simpliforceps } \\
\text { Total }\end{array}$ & 6 & 16 & 1 & 17 \\
\hline $\begin{array}{l}\text { Culiseta } \\
\begin{array}{l}\text { Culiseta allotheobaldia } \\
\text { longeareolata* }\end{array}\end{array}$ & 8 & $\mathbf{2 2}$ & $\mathbf{2}$ & $\mathbf{2 4}(\mathbf{1 5 \% )}$ \\
$\begin{array}{l}\text { Total } \\
\text { Anopheles }\end{array}$ & & $\mathbf{8}$ & $\mathbf{2}$ & $\mathbf{1 0}(\mathbf{6 \% )}$ \\
$\begin{array}{l}\text { Anopheles coustani } \\
\text { A. squamous }\end{array}$ & 1 & 11 & 0 & 11 \\
Total & 1 & 1 & 1 & 2 \\
\hline
\end{tabular}

\begin{tabular}{|c|c|c|c|c|}
\hline \multicolumn{5}{|l|}{ Toxorhyncites } \\
\hline $\begin{array}{l}\text { Toxorhyncites toxorhyncites } \\
\text { brevipalpis }\end{array}$ & 2 & 2 & 0 & 2 \\
\hline Total & & 2 & 0 & $2(1 \%)$ \\
\hline \multicolumn{5}{|l|}{ Aedes } \\
\hline $\begin{array}{l}\text { Aedes aedimorphus } \\
\text { albocephalus }\end{array}$ & 1 & 1 & 0 & 1 \\
\hline Total & & 1 & 0 & $1(0.6 \%)$ \\
\hline
\end{tabular}

Unknown (unidentifiable/missing parts/immature)

\begin{tabular}{llll} 
& 352 & 16 & 368 \\
Grand Total & 490 & 34 & 524 \\
& $(94 \%)$ & $(6 \%)$ & \\
\hline
\end{tabular}

Names in bold indicate the mosquito genera identified. Generic prevalence is indicated in brackets; known vectors are denoted by *. ${ }^{5}$ The Culex culex pipiens complex includes Culex c. pipiens and C. quinquefasciatus which are often indistinguishable from each other.

abundance and temperature $(p=0.02)$; and between mosquito prevalence and dissolved oxygen $(p=0.05)$. Dissolved oxygen and $\mathrm{pH}$ were positively correlated with each other $\left(r^{2}=0.52 ; p=0.02\right)$, as were salinity and latitude $\left(r^{2}=0.39 ; p<0.01\right)$.
Variation in infection prevalence with rainfall and location Plasmodium prevalence varied significantly across districts (see Figure $6 ; F_{3,15}=8.21 ; p=0.002$ ). Sites in the west coast district displayed infection prevalences of $23-70 \%$ (mean 44\%; s. d. = 9.56). The west coast district was the driest region from which birds were sampled, with sites in that region receiving between 200$400 \mathrm{~mm}$ rainfall annually. Sites in the wetter districts of the City of Cape Town and Boland (which received between $600-800 \mathrm{~mm}$ rainfall) had lower mean infection prevalences of $7 \%$ and $12 \%$ respectively. Plasmodium prevalence was also correlated with latitude $(p=0.04$; see Table 3).

With the exception of Strandfontein (which falls within the City of Cape Town), the largest number of mosquitoes were caught in and around the Boland District, whereas the lowest number were caught in the West Coast District (Figure 7). This variation in mosquitoes caught across districts was notable, although not significant $\left(F_{3,15}=3.03 ; p=0.06\right)$.

Variation in infection prevalence with rainfall followed a seasonal pattern, with wetter sites generally displaying lower infection prevalences (Figures 8 and 9). Infection prevalence showed significant correlation with rainfall $\left(r^{2}=-0.43 ; p=0.05\right)$ and days of rainfall $\left(r^{2}=-0.49\right.$; $p=0.02$ ) two months prior to sampling across seasons. Seasonally, infection prevalence was negatively related to rainfall during winter sampling months $\left(r^{2}=-0.43\right.$; $p=0.05)$ and days of rainfall 2 months prior $\left(r^{2}=-0.51\right.$; $p=0.02$ ).

\section{Multiple regression analysis}

Plasmodium prevalence was best described by seasonal factors (with winter as the significant season); mosquito prevalence; salinity; and rainfall at a lag of 4 months (Table 4). Rainfall during the sampling month was also a relevant factor, although not as influential. Significant reductions in the goodness of fit of the best model occurred when any explanatory variables were omitted. Season caused the greatest reduction when omitted (likelihood ratio $=17.47 ; p<0.001$ ) and rainfall (at four months) the least reduction (likelihood ratio $=4.16$; $p=0.04$ ).

\section{Discussion}

Plasmodium infections were widespread across sampling sites, with only four sites having no infected birds. The majority of mosquitoes (66\%) were caught at one wetland, Strandfontein (STR). Strandfontein was amongst the sites receiving the highest annual rainfall $(503 \mathrm{~mm})$, which was likely a primary contributing factor to the high mosquito catch. Strandfontein is also a sewage treatment plant, and it is possible that the high nutrient content of the water enhanced mosquito breeding 


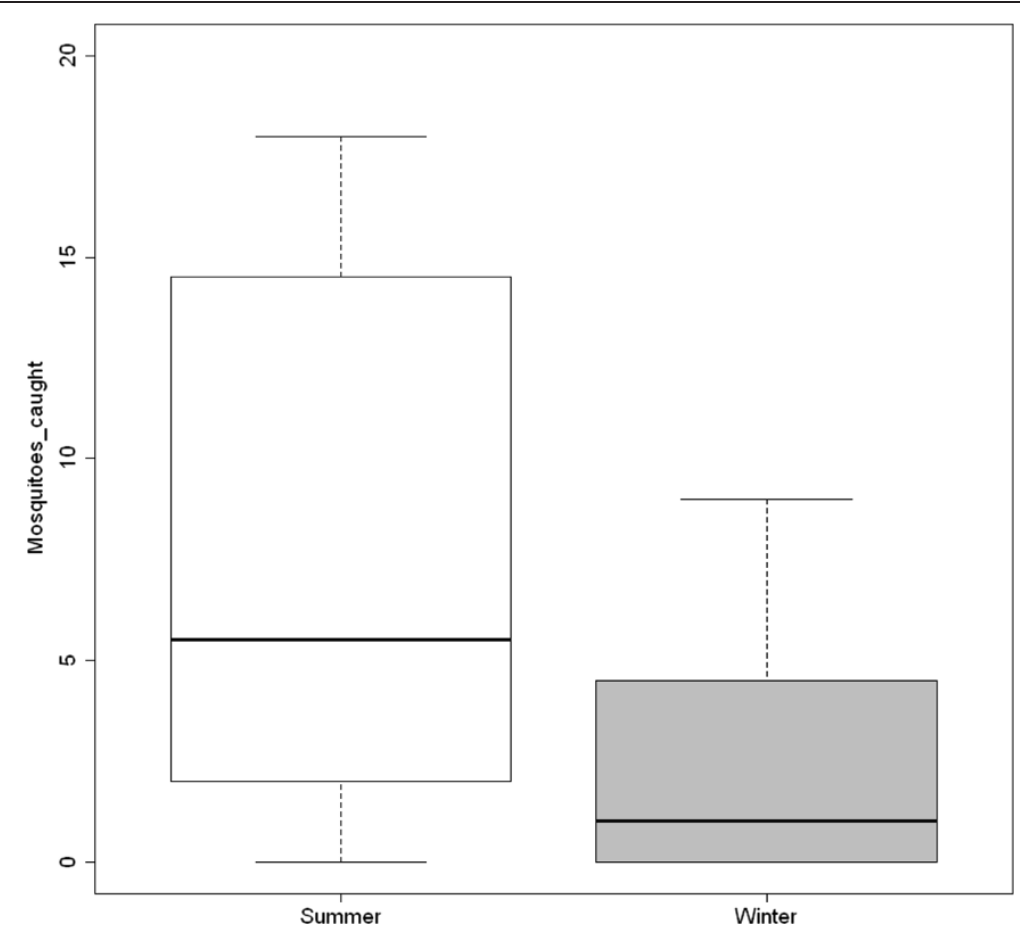

Figure 5 Seasonal variation in the mean number of mosquitoes caught per site $(n=524 ; p=0.04)$.

success at this site $[41,42]$. However, because no nutrient data were collected in this study, this suggestion remains open.

Temperature and $\mathrm{pH}$ displayed the most marked variations between seasons (Table 2), which is consistent with previous findings $[43,44]$. Temperature varied with vector abundance, which was also consistent with previous findings on associations between water quality and malaria vectors $[10,15]$. These elements did not display any apparent influence on either mosquito or Plasmodium prevalence (see Figures 1 and 5). Otherwise prevalence patterns were synchronized across seasons, with higher prevalences seen in summer than in winter (Figures 2, 4 and 5). Seasonal factors tend to have contrasting effects upon different vector species; seasonal variation in the prevalence of vector-borne diseases is well documented [45], and our observed patterns are in accordance with findings from other studies of avian malaria $[46,47]$, as well as other vector-borne diseases [48].

Sites with the heaviest infection prevalence were also the sites with the lowest mosquito catch. Three (out of five) sites with heavy infections were situated in the west coast district of the Western Cape; no mosquitoes were caught at these sites, despite an equal sampling effort across all sites (Figures 6 and 7). Because mosquitoes are dependent upon water for breeding it is expected that they would be more abundant in wetter areas. Mosquito catch size across sites did indeed vary with rainfall patterns (Figure 7), which is supportive and consistent with previous findings $[49,50]$. The West Coast District is much drier than other sampled districts in the province [51], receiving $\leq 200 \mathrm{~mm}$ of rainfall annually compared to sites within the Cape Town metropole $(\geq$ $700 \mathrm{~mm}$ ), and sites in the Boland and Overberg Districts $(400-600 \mathrm{~mm})$. The western coast of the Western Cape is one of the driest regions in South Africa, with climate modelling indicating that it will become still drier over the coming years [52]. Observed seasonal patterns of infection and mosquito abundance are in contrast to patterns observed elsewhere in the country [53], most likely because the Western Cape is a winterrainfall region, unlike the rest of South Africa. Rainfall had both a direct and indirect impact upon infection prevalence (Figures 8 and 9), and also featured in models explaining variation in prevalence (Table 4).

Seasonal abundance was the only apparent pattern of analogous co-variation between mosquito and infection prevalence. Otherwise, the notable outcome was the contrasting relationship between mosquito and infection prevalence. The two factors displayed a negative correlation with each other, although the expectation was that they would co-vary positively. The negative co-variance of mosquito prevalence and infection prevalence is apparently concurrent with observations from previous malaria studies in Africa, which report lag responses in mosquito abundance and infection prevalence, both with each other and with rainfall $[9,35]$. Similar studies in Africa also found that at several sampling sites with high 
Table 2 Seasonal variation in sampled water quality variables

\begin{tabular}{lllll}
\hline & Dissolved oxygen & Temperature & pH & Salinity \\
\hline Summer range & $2.97-11.54$ & $17.29-33.22$ & $5.40-9.31$ & $0.00-6.52$ \\
Summer mean & 7.02 & $\mathbf{2 7 . 2 8}$ & $\mathbf{7 . 9 4}$ & 0.77 \\
Winter range & $2.07-14.02$ & $10.72-19.20$ & $6.85-10.11$ & $0.00-2.18$ \\
Winter mean & 7.76 & $\mathbf{1 4 . 8 0}$ & $\mathbf{8 . 4 3}$ & 0.63 \\
\hline
\end{tabular}

Numbers in bold indicate significant seasonal variation, which occurred with temperature $(p<0.001)$ and $\mathrm{pH}(p=0.04)$.

infection prevalences (of Plasmodium falciparum), few to no mosquitoes were caught $[35,54]$. Additionally, the entomologic inoculation rate was low in comparison to infection prevalence, and varied widely in small geographic regions of sampling.

Taken in context, the gathered data thus suggest that malarial infection prevalence is not dependent upon current mosquito abundance - leading to three parsimonious conclusions. The first is that the patterns of prevalence observed here are indicative of malarial and mosquito prevalence exhibiting a lag response throughout the year in response to the same driving factors. This potentially explains the contrasting relationship between the two prevalences, and the observed correlations with rainfall in the months prior to sampling. The second conclusion is that a low number of mosquitoes are still capable of infecting a wide range of hosts. The third conclusion is that birds were not infected at the wetlands at which they were caught. As the majority of sampled birds were territorial wetland passerines, and predominantly residential [22], it was assumed that these birds were infected on site. However, there remains the possibility that species sampled were more mobile than current knowledge suggests - potentially leading to a scenario where birds were caught at one wetland but actually infected at another location. This possibility is further complicated by the fact that wild passerines can carry chronic lifelong infections of avian malaria, which can have various effects (depending on the host species) on host mobility and reproductive success $[55,56]$. For example in this study, a significant variation in species infection prevalence with season occurred only in
Southern Red Bishops, but not with other sampled weaver species (Figure 2). Incorporating movement data (of sampled bird species) into future analyses would serve to confirm the significance of host movement in observed avian malarial infections. Also of interest was that many wetland sites with a low mosquito catch had exposed banks with little to no vegetation within the set trapping areas. Water with high detrital loads (from erosion or a similar event) is not conducive to mosquito breeding, and these wetlands may have acted as a deterrent to mosquito breeding [57]. Leisnham et al. [57] similarly noted that the level and type of vegetation cover mattered in mosquito breeding success. Hence mosquito prevalence here was potentially further affected by variation in vegetation cover and type, or changing landscape features. A final factor for consideration is that several mosquito species caught in this study may have been vectors for avian malaria, but are not yet known as vectors; leading to a potential underestimation of vector abundance. The fairly recent reports of new vector species in Africa [31] highlight how limited vector knowledge is pertaining to avian malaria. Consequently, our conclusions are restricted by the lack of current knowledge about known vectors for avian malaria, particularly in sub-saharan Africa.

Salinity was the only element of water quality that exhibited a direct correlation with Plasmodium infection prevalence (Table 3). Infection also varied with latitude, whereas salinity and latitude were significantly and positively correlated $\left(r^{2}=0.39 ; p=0.01\right)$. The trend in infection prevalence was apparent across sampling regions (Figure 6), suggesting that location is an influential factor

Table 3 Values for Pearson's coefficient $\left(r^{2}\right)$ describing co-variation between water quality elements, Plasmodium and vector abundance $(* p \leq 0.05)$

\begin{tabular}{|c|c|c|c|c|c|c|}
\hline & Temp & $\mathrm{pH}$ & DO & Salinity & Latitude & Longitude \\
\hline \multicolumn{7}{|l|}{ Plasmodium prevalence } \\
\hline & -0.21 & 0.10 & 0.18 & $0.39^{*}$ & $0.33^{*}$ & -0.13 \\
\hline \multicolumn{7}{|l|}{ Mosquitoes } \\
\hline Mosquito prevalence/WSTR & $0.09 /-0.12$ & $0.008 / 0.28$ & $0.10 / 0.44^{*}$ & $-0.33 /-0.33$ & $-0.16 /-0.23$ & $-0.13 / 0.27$ \\
\hline Vector abundance & $0.37^{*}$ & -0.11 & 0.003 & -0.16 & -0.17 & -0.05 \\
\hline
\end{tabular}

WSTR represents mosquito prevalence excluding Strandfontein. Temp = Temperature; DO = Dissolved oxygen. Numbers in bold indicate significant correlation. 


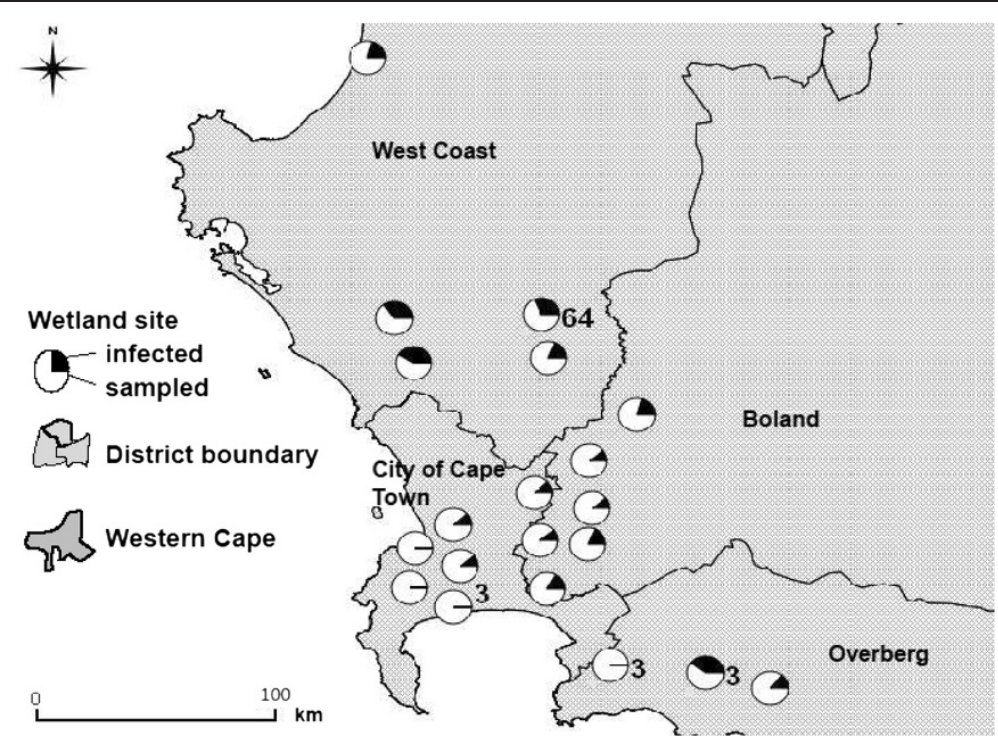

Figure 6 Map showing infection prevalence by site (overall site prevalence $=\mathbf{0 . 2 7} ; \mathbf{n}=\mathbf{2 0}$ ). Numeric labels indicate sites with the smallest and largest sample sizes. There was a significant pattern of variation in Plasmodium prevalence with location $(p<0.001$; see Table 2$)$, with most heavily infected sites situated in the West Coast District.

in both wetland salinity and infection prevalence. The link between salinity and Plasmodium may be an effect of Plasmodium prevalence being higher in the summer, when waterbodies tend to be more saline as a result of increased evaporation [58,59]. It was also expected that salinity would increase with proximity to the sea - instead the opposite trend was observed. The locational trend in salinity variance implies there is an additional underlying factor influencing water quality, such as the geology of the landscape within which the wetland occurs. For instance, several sites in the West Coast District occurred in areas typified by geology such as shales and batholiths, which occur around Malmesbury and Darling respectively [60]. The chemistry of these volcanic rocks $[60,61]$, combined with the land use of the surrounding areas [17], may subsequently influence water quality.

Plasmodium prevalence was best described by a model incorporating locational and seasonal factors together with

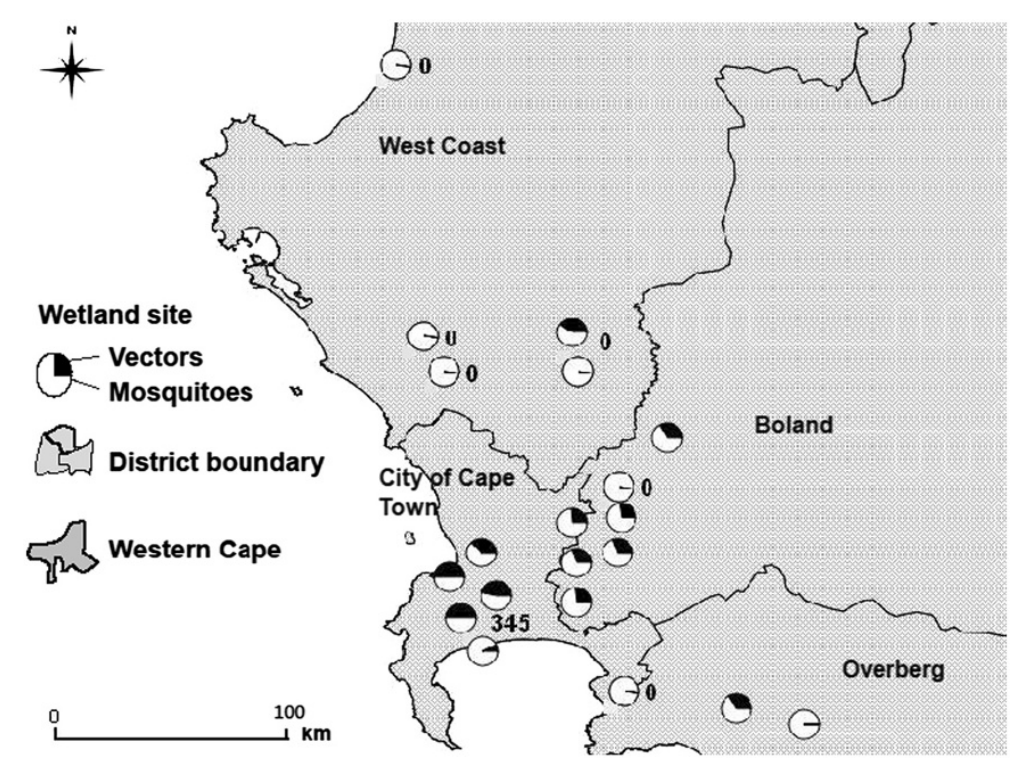

Figure 7 Map displaying prevalence of mosquitoes and potential vectors caught per site (total catch $=516 ; \mathbf{n}=$ in 20 sites). Numeric labels indicate sites with the smallest and largest sample sizes; notably, no mosquitoes were caught at 6 sites. The most mosquitoes were trapped in the Boland and Cape metropolitan districts. 


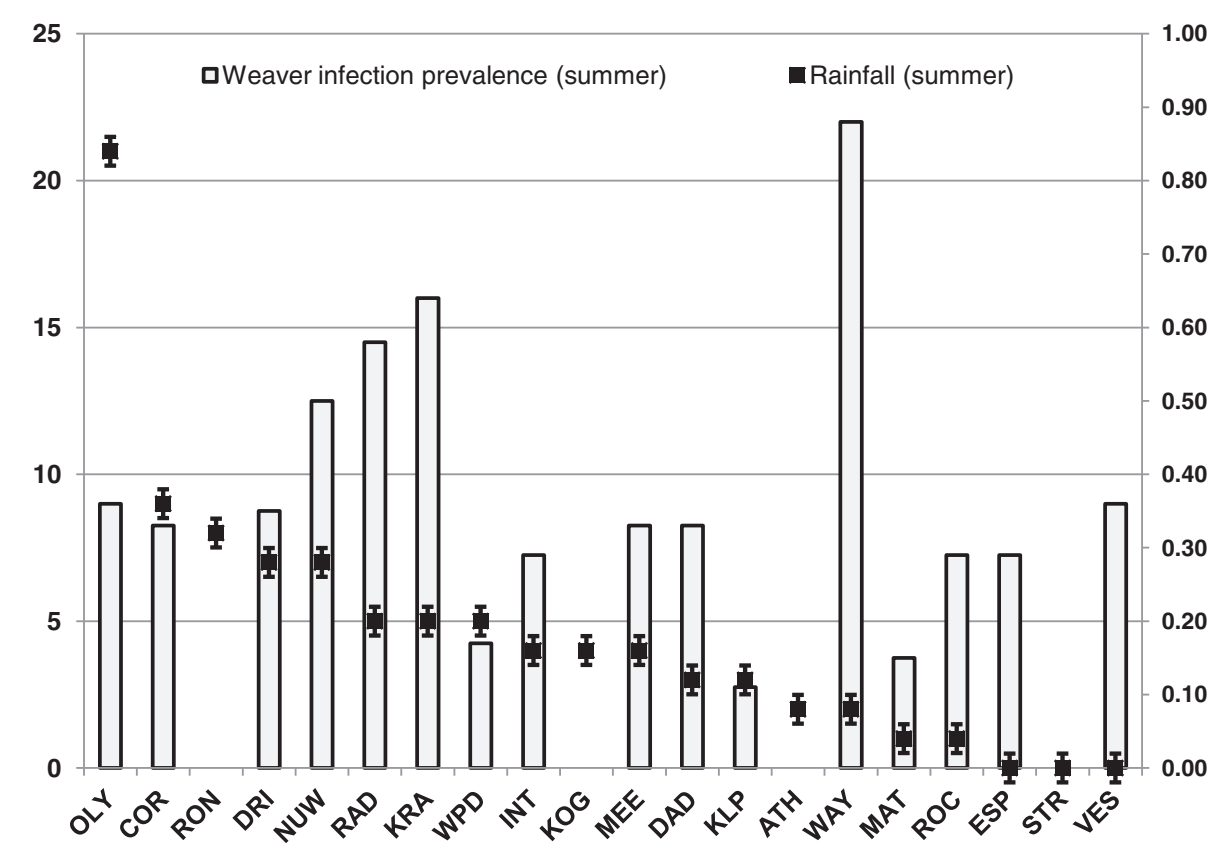

Figure 8 Rainfall (mm, left axis) and site prevalence (right axis) in summer sampling months (standard deviation bars $=+/-0.49$ ).

salinity, rainfall and mosquito prevalence (Table 4). With the exception of mosquito prevalence, these factors were all influential to infection prevalence. Mosquito prevalence exerted an indirect influence in the Plasmodium model, further suggesting that the relationship between infected birds and mosquito prevalence is non-linear, and supporting the argument that mosquito and infection prevalences vary temporally in a lag pattern with each other.

\section{Conclusions}

The prevailing outcome of this analysis was that avian malaria prevalence and mosquito abundance did not display

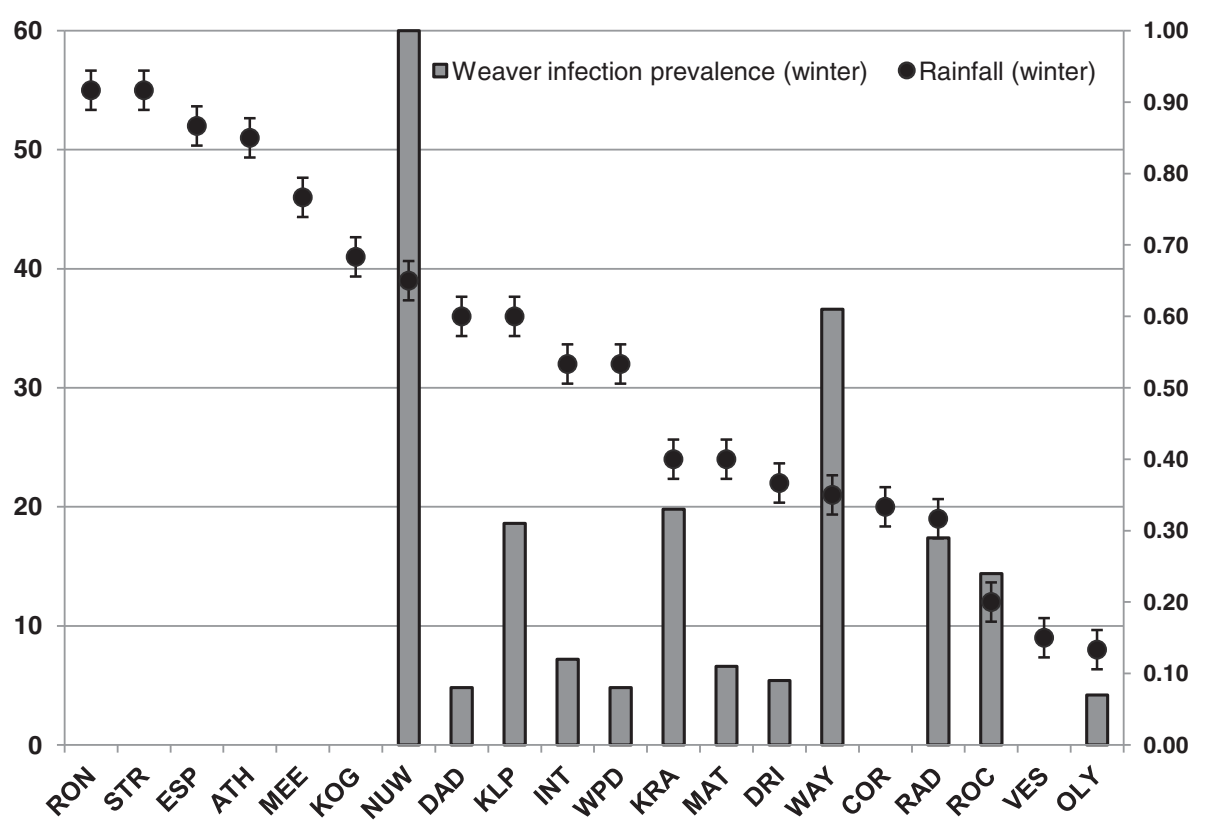

Figure 9 Rainfall (mm, left axis) and site prevalence (right axis) in winter sampling months (standard deviation $=+/-1.65$ ). The pattern of higher infection prevalence with less rainfall is more apparent during winter. 
Table 4 Models best describing Plasmodium prevalence $(n=20)$

\begin{tabular}{|c|c|c|c|c|c|c|}
\hline Factor & Coefficient estimate ( \pm S.E.) & $P$ & d.f. & Residual deviance & AIC & $\Delta \mathrm{AIC}$ \\
\hline \multicolumn{7}{|c|}{ Plasmodium (best-fit model) } \\
\hline Intercept & $-0.86 \pm 0.17$ & $<0.001$ & 34 & 69.37 & 179.54 & - \\
\hline Winter & $-0.78 \pm 0.18$ & $<0.001$ & & & & \\
\hline Salinity & $0.20 \pm 0.05$ & $<0.001$ & & & & \\
\hline Mosquito prevalence & $-5.85 \pm 2.00$ & $<0.005$ & & & & \\
\hline Rainfall (at 4 months) & $-0.01 \pm 0.008$ & $<0.05$ & & & & \\
\hline \multicolumn{7}{|c|}{ Plasmodium model 2} \\
\hline Intercept & $-1.13 \pm 0.11$ & $<0.001$ & 36 & 75.53 & 181.70 & 2.16 \\
\hline Winter & $-0.58 \pm 0.16$ & $<0.001$ & & & & \\
\hline Salinity & $0.25 \pm 0.05$ & $<0.001$ & & & & \\
\hline Mosquito prevalence & $-6.80 \pm 1.99$ & $<0.001$ & & & & \\
\hline \multicolumn{7}{|c|}{ Plasmodium model 3} \\
\hline Intercept & $-1.10 \pm 0.11$ & $<0.001$ & 35 & 72.80 & 182.97 & 3.43 \\
\hline Winter & $-0.41 \pm 0.25$ & $<0.001$ & & & & \\
\hline Salinity & $0.25 \pm 0.05$ & $<0.001$ & & & & \\
\hline Mosquito prevalence & $-6.55 \pm 2.01$ & $<0.001$ & & & & \\
\hline Rainfall (sampling month) & $-0.007 \pm 0.009$ & 0.40 & & & & \\
\hline \multicolumn{7}{|c|}{ Plasmodium model 4} \\
\hline Intercept & $-1.01+0.16$ & $<0.001$ & 36 & 74.17 & 184.89 & 5.35 \\
\hline Salinity & $0.22+0.06$ & $<0.001$ & & & & \\
\hline Mosquito prevalence & $-5.46+1.97$ & 0.006 & & & & \\
\hline Rainfall (sampling month) & $-0.02+0.01$ & $<0.005$ & & & & \\
\hline Rainfall (at 4 months) & $-0.01+0.01$ & 0.32 & & & & \\
\hline \multicolumn{7}{|c|}{ Plasmodium model 5} \\
\hline Intercept & $-8.50 \pm 0.17$ & $<0.001$ & 36 & 80.72 & 188.90 & 9.36 \\
\hline Winter & $-0.86 \pm 0.18$ & $<0.001$ & & & & \\
\hline Salinity & $0.21 \pm 0.06$ & $<0.001$ & & & & \\
\hline Rainfall (at 4 months) & $-0.02 \pm 0.01$ & $<0.005$ & & & & \\
\hline
\end{tabular}

Models are ranked using $\triangle \mathrm{AIC}$ and range between $\triangle \mathrm{AIC} \leq 10$.

analogous co-variation. Instead, they varied in a contrasting fashion and were indirectly linked by season and rainfall. The presence of infected birds at a site typically indicates the presence of a vector species; however, at many infected sites (particularly in the West Coast district of the Western Cape) no mosquitoes were caught. The same result has been reported in previous malarial studies [35,54], which also demonstrated temporal lag responses between mosquito prevalence, infection prevalence and rainfall. The best-supported explanation for observed prevalence patterns is a probable lag response between vector prevalence and rainfall. Another trend was that local environmental variation played a prominent role in avian malarial infection prevalence in the Western Cape. In general, however, the findings presented here support the argument that avian malaria prevalence patterns vary with both host and vectorrelated factors.

\section{Competing interests}

The authors declare that they have no competing interests.

Authors' contributions

SO contributed to the design of the study; conducted fieldwork, mosquito identification and data analysis; and wrote the first draft of the manuscript. GC contributed to the design of the study, data analysis, and editing. $\mathrm{PH}$ contributed to the design of the study and editing. $\mathrm{PH}$ passed away before the manuscript was finalized. All authors have read and approved the final manuscript.

\section{Acknowledgements}

We are grateful to Jeffrey Peters for facilitating the molecular analysis of samples. We thank David Nkosi for his assistance with fieldwork and Mercedes Grome for her assistance with the molecular analysis of samples. We are also grateful to Professor Maureen Coetzee for her assistance with the identification of mosquito species. The manuscript was improved by comments from S. Bensch and R.V.M. Sehgal. This work was funded by grants from the DST/NRF Centre of Excellence at the Percy FitzPatrick Institute of African Ornithology and the International Foundation for Science (IFS). 
Received: 23 August 2013 Accepted: 23 October 2013

Published: 25 October 2013

\section{References}

1. Patz JA, Grazcyk TK, Geller N, Vittor AY: Effects of environmental change on emerging parasitic diseases. Int J Parasitol 2000, 30:1395-1406.

2. Bensch S, Stjernman M, Hasselquist D, Ostman O, Hansson B, Westerdahl H, Torres Pinheiro R: Host specificity in avian blood parasites: a study of Plasmodium and Haemoproteus mitochondrial DNA amplified from birds. Proc R Soc Lond B Biol Sci 2000, 267:1583-1589.

3. Beadell JS, Gering E, Austin J, Dumbacher JP, Peirce MA, Pratt TK, Atkinson $C T$, Fleischer RC: Prevalence and differential host-specificity of two avian blood parasite genera in the Australo-Papuan region. Mol Ecol 2004, 13:3829-3844.

4. Ricklefs RE, Fallon SM, Bermingham E: Evolutionary relationships, cospeciation and host switching in avian malaria parasites. Syst Biol 2004, 53:111-119.

5. Valkiūnas G: Avian malaria parasites and other haemosporidia. Boca Raton: CRC Press; 2005

6. Smith DL, Dushoff J, McKenzie FE: The risk of a mosquito-borne infection in a heterogeneous environment. PLOS Biol 2004, 2:e368.

7. Rueda LM, Patel K, Axtell RC, Stinner RE: Temperature-Dependent Development and Survival Rates of Culex quinquefasciatus and Aedes aegypti (Diptera: Culicidae). J Med Entomol 1990, 27:892-898.

8. Mbogo CNM, Snow RW, Khamala CP, Kabiru EW, Ouma JH, Githure Jl, Marsh K, Beier JC: Relationships between Plasmodium falciparum transmission by vector populations and the incidence of severe disease at nine sites on the Kenyan coast. Am J Trop Med Hyg 1995, 52:201-206.

9. Greenwood BM: The epidemiology of malaria. Ann Trop Med Parasitol 1997, 91:763-769.

10. Alles HK, Mendis KN, Carter R: Malaria Mortality Rates in South Asia and in Africa: Implications for Malaria Control. Parasitol Today 1998, 14:369-375.

11. Shepherd JM: A review of current investigations of urban-induced rainfall and recommendations for the future. Earth Interact 2005, 9:1-27.

12. Min SK, Zhang X, Zwiers FW, Heger GC: Human contribution to more- intense precipitation extremes. Nature 2011, 470:378-381.

13. Garamszegi $L Z$, Moller AP: Prevalence of avian influenza and host ecology. Proc R Soc Lond B Biol Sci 2007, 274:2003-2012.

14. McKenzie VJ, Townsend AR: Parasitic and infectious disease responses to changing global nutrient cycles. Ecohealth 2007, 4:384-396.

15. Kengluecha A, Singhasivanon P, Tiensuwan M, Jones JW, Sithiprasasna R: Water quality and breeding habitats of Anopheles mosquito in Northwestern Thailand. Southeast Asian J Trop Med Public Health 2005, 36:46-53.

16. Wood MJ, Cosgrove CL, Wilkin TA, Knowles SCL, Day KP, Sheldon BC: Within-population variation in prevalence and lineage of distribution of avian malaria in blue tits, Cyanistes caeruleus. Mol Ecol 2007, $15: 3263-3273$

17. Okanga S, Cumming GS, Hockey PAR, Peters JL: Landscape structure influences avian malaria ecology in the Western Cape, South Africa. Landscape Ecol:. doi: 10.1007/s10980-013-9949-y.

18. Paracuellos $M$, Telléria JL: Factors affecting the distribution of a waterbird community: the role of habitat configuration and bird abundance. Waterbirds 2004, 27:446-453.

19. Beadell JS, Ishtiaq F, Covas R, Melo M, Warren BH, Atkinson $C T$, Bensch $S$, Graves GR, Jhala W, Peirce MA, Rahmani AS, Fonseca DM, Fleischer RC: Global phylogeographic limits of Hawaii's avian malaria. Proc R Soc Lond B Biol Sci 2006, 273:2935-2944.

20. Schultz A, Underhill LG, Earlé R, Underhill G: Seasonality, distribution and taxonomic status of avian haemosporidian parasites within the Greater Cape Town area, South Africa. Ostrich 2011, 82:141-153.

21. Graczyk TK, Brossy JJ, Plos A, Stoskopf MK: Avian malaria seroprevalence in Jackass penguins (Spheniscus demersus) in South Africa. J Parasitol 1995, 81:703-707.

22. Hockey PAR, Dean WRJ, Ryan PG: Roberts - Birds of Southern Africa. VIlth edition. Cape Town: The trustees of the John Voelcker bird book fund; 2005.

23. Sutherland WJ, Newton I, Green RE: Bird Ecology and Conservation: A handbook of techniques, Techniques in Ecology and Conservation Series. Oxford: Oxford University Press; 2004.
24. Cumming GS, Shepard E, Okanga S, Caron A, Ndlovu M, Peters J: Host associations, biogeography, and phylogenetics of avian malaria in southern African waterfowl. Parasitol 2013, 140:193-201.

25. Tamura K, Peterson D, Peterson N, Stecher G, Nei M, Kumar S: MEGA5: molecular evolutionary genetics analysis using maximum likelihood, evolutionary distance, and maximum parsimony methods. Mol Biol Evol 2011, 28:2731-2739.

26. Ronquist F, Huelsenbeck JP: MRBAYES 3: Bayesian phylogenetic inference under mixed models. Bioinformatics 2003, 19:1572-1574.

27. Ronquist F, Teslenko M, van der Mark P, Ayres DL, Darling A, Höhna S, Larget B, Liu L, Suchard MA, Huelsenbeck JP: MrBayes 3.2: efficient Bayesian phylogenetic inference and model choice across a large model space. Syst Biol 2012, 61:539-542.

28. Soltis $\mathrm{PS}$, Soltis DE: Applying the bootstrap in phylogeny reconstruction. Stat Sci 2003, 18:256-267.

29. Jupp P: Mosquitoes of Southern Africa. Hartebeespoort, South Africa: Ekogilde CC Publishers; 1996.

30. Russell PF, Mohan BN: Some mosquito hosts to avian plasmodia with special reference to Plasmodium gallinaceum. J Parasitol 1942, 28:127-129.

31. Njabo KY, Cornel AJ, Sehgal RNM, Loiseau C, Buermann W, Harrigan RJ, Pollinger J, Valkiūnas G, Smith TB: Coquillettidia (Culicidae, Diptera) mosquitoes are natural vectors of avian malaria in Africa. Malar J 2009, 8:193.

32. Ventim R, Ramos JA, Osório H, Lopes RJ, Pérez-Tris J, Mendes L: Avian malaria infections in western European mosquitoes. Parasitol Res 2012, 111:635-645.

33. Famine Early Warning Systems net portal. http://www.earlywarning.usgs. gov/fews.

34. Xie P, Arkin PA: Analyses of global monthly precipitation using gauge observations, satellite estimates and numerical model predictions. J Climate 1996, 9:840-858.

35. Mbogo CNM, Mwangangi JM, Nzovu J, Gu W, Yan G, Gunter JT, Swalm C, Keating J, Regens JL, Shililu JI, Githure JI, Beier JC: Spatial and temporal heterogeneity of Anopheles mosquitoes and Plasmodium falciparum transmission along the Kenyan coast. Am J Trop Med Hyg 2003, 68:734-742.

36. R Development Core Team: $R$ : A language and environment for statistical computing. R Foundation for Statistical Computing. http://www.R-project.org

37. Crawley MJ: Statistics: An introduction using R. Chicester: John Wiley and Sons Ltd; 2005.

38. Box GEP, Cox DR: An analysis of transformations. J Roy Stat Soc 1964, 26:211-252.

39. Smith RA, Schwarz GE, Alexander RB: Regional interpretation of waterquality monitoring data. Water Resour Res 1997, 33:2781-2798.

40. Upton G, Cook I: Understanding statistics. Oxford: Oxford University Press; 1996.

41. Arimoro F, Ikomi RB, Iwegbue CMA: Water quality changes in relation to Diptera community patterns and diversity measured at an organic effluent impacted stream in the Niger Delta, Nigeria. Ecol Indic 2007, 7:541-552.

42. Chaves LF, Keough CL, Vazquez-Propokec GM, Kitron UD: Combined sewage overflow enhances oviposition of Culex quinquefasciatus (Diptera: Culicidae) in urban areas. J Med Entomol 2009, 46:220-226.

43. Morris S, Taylor AC: Diurnal and seasonal variation in physic-chemical conditions within intertidal rock pools. Estuar Coast Shelf Sci 1983, 17:339-355

44. Vega M, Pardo R, Barrado E, Bedán L: Assessment of seasonal and polluting effects on the quality of river water by exploratory data analysis. Water Res 1998, 32:3581-3592.

45. Lafferty KD: The ecology of climate change and infectious diseases. Ecology 2009, 90:888-900.

46. Schrader MS, Walters EL, James FC, Greiner EC: Seasonal prevalence of a haematozoan parasite of red-bellied woodpeckers (Melanerpes carolinus) and its association with host condition and overwinter survival. Auk 2003, 120:130-137.

47. Cosgrove CL, Wood MJ, Day KP, Sheldon BC: Seasonal variation in Plasmodium prevalence in a population of blue tits Cyanistes caeruleus. $J$ Anim Ecol 2008, 77:540-548.

48. Hay SI, Snow RW, Rogers DJ: Predicting malaria seasons in Kenya using multitemporal meteorological satellite sensor data. Trans $R$ Soc Trop Med Hyg 1998, 92:12-20. 
49. Galardo AKR, Zimmerman RH, Lounibos LP, Young LJ, Galardo CD, Arruda M, D'Almeida Couto AAR: Seasonal abundance of Anopheline mosquitoes and their association with rainfall and malaria along the Matapí river, Amapí, Brazil. Med Vet Entomol 2009, 23:335-349.

50. Mwangangi JM, Muturi EJ, Mbogo CM: Seasonal mosquito larval abundance and composition in Kibwezi, lower eastern Kenya. J Vector-Borne Dis 2009, 46:65-71.

51. Schulze RE, Lynch SD: Annual Precipitation. In South African Atlas of Climatology and Agrohydrology: Water Research Commission, Pretoria, RSA WRC Report 1489/1/06, Section 6.2; 2007. Edited by Schulze RE. ; 2007.

52. Lumsden TG, Schulze RE, Hewitson BC: Evaluation of potential changes in hydrologically relevant statistics of rainfall in southern Africa under conditions of climate change. Water SA (Online) 2009, 35:649-656.

53. Earlé RA, Little RM, Crowe T: Haematozoa of greywing francolin from the Stormberg, Eastern Cape province, South Africa. S Afr J Wildl Res 1992, 22:94-97.

54. Beier JC, Killeen GF, Githure JJ: Short report: entomologic inoculation rates and Plasmodium falciparum malaria prevalence in Africa. Am J Trop Med Hyg 1999, 61:109-113.

55. Yorinks $\mathrm{N}$, Atkinson CT: Effects of malaria on activity budgets of experimentally infected juvenile Apapane (Himatione sanguinea). Auk 2000, 117:731-738

56. Kilpatrick AM, LaPointe DA, Atkinson CT, Woodworth BL, Lease JK, Reiter ME, Gross K: Effects of chronic avian malaria (Plasmodium relictum) infection on reproductive success of Hawaii Amakihi (Hemignathus virens). Auk 2006, 123:764-774.

57. Leisnham PT, Lester PJ, Slaney DP, Weinstein P: Anthropogenic landscape change and vectors in New Zealand: effects of shade and nutrient levels on mosquito productivity. Ecohealth 2004, 1:306-316.

58. Ridd PV, Stieglitz P: Dry season salinity changes in arid estuaries fringed by mangroves and saltflats. Estuar Coast Shelf Sci 2002, 54:1039-1049.

59. Jolly ID, McEwan KL, Holland KL: A review of groundwater-surface water interactions in arid/semi-arid wetlands and the consequences of salinity for wetland ecology. Ecohydrology 2008, 1:43-58.

60. Scheepers R: Geology, Geochemistry and petrogenesis of Late Precambrian S-, I- and A-type granitoids in the saldania belt, Western Cape Province South Africa. J Afr Earth Sci 1995, 21:35-58

61. Sliva L, Williams DD: Buffer zone versus whole catchment approaches to studying land use impact on river water quality. Water Res 2001, 35:3462-3472.

doi:10.1186/1475-2875-12-370

Cite this article as: Okanga et al:: Avian malaria prevalence and mosquito abundance in the Western Cape, South Africa. Malaria Journal 2013 12:370

\section{Submit your next manuscript to BioMed Central and take full advantage of:}

- Convenient online submission

- Thorough peer review

- No space constraints or color figure charges

- Immediate publication on acceptance

- Inclusion in PubMed, CAS, Scopus and Google Scholar

- Research which is freely available for redistribution 